\title{
Laudatio Académica: Tres Colosos
}

\section{Academic Laudatio: Three Colossus}

\section{Eugenio Pérez Montás}

Doctor Honoris Causa en Arquitectura, profesor fundador y asesor vitalicio

de la Universidad Nacional Pedro Henríquez Ureña

Santo Domingo, República Dominicana

centroaltosestudios@gmail.com

Fecha de recepción: 30 de mayo de 2017.

Fecha de aceptación: 15 de julio de 2017.

Favor de citar este artículo de la siguiente forma:

Pérez Montás, E. (2017). Laudatio Académica: Tres colosos.

Revista AULA. Vol. 61, Número 1, julio-diciembre 2017. Santo Domingo: Amigo del Hogar

\section{RESUMEN}

Indagar en las vidas y legados de tres hombres, ciudadanos ejemplares, reconocidos por su Alma Máter con los máximos laudos de profesores honoris causa, es una lección imperecedera para los actuales y futuros estudiantes de la Universidad. Aprender de ellos, reconocerlos por su individual noción de éxito, por su preocupación por los demás y por el justo sentido de su liderazgo es recoger parte importante del legado que la UNPHU ha construido por poco más de medio siglo. Es, también, comprender el rol que estamos llamados a jugar los profesionales académicos en el devenir de la sociedad dominicana.

Palabras clave: Emprendimiento, éxito, humanismo, laudatio académica, legado, UNPHU

\begin{abstract}
To inquire into the lives and legacies of three men, exemplary citizens, recognized by their Alma Mater with the highest awards of honorary teachers; is an everlasting lesson for current and future students of the University. To learn from them, to recognize them by their individual notion of success, by their concern for others and by the just sense of their leadership; means, to gather an important part of the legacy that UNPHU has built, for little more than half a century. It is also, to understand the role that academic professionals are called to play in the future of Dominican society.
\end{abstract}

Keywords: Academic laudatio, entrepreneurship, humanism, legacy, success, UNPHU 
Laudatio Académica: Tres colosos

Academic Laudatory: Three colossus

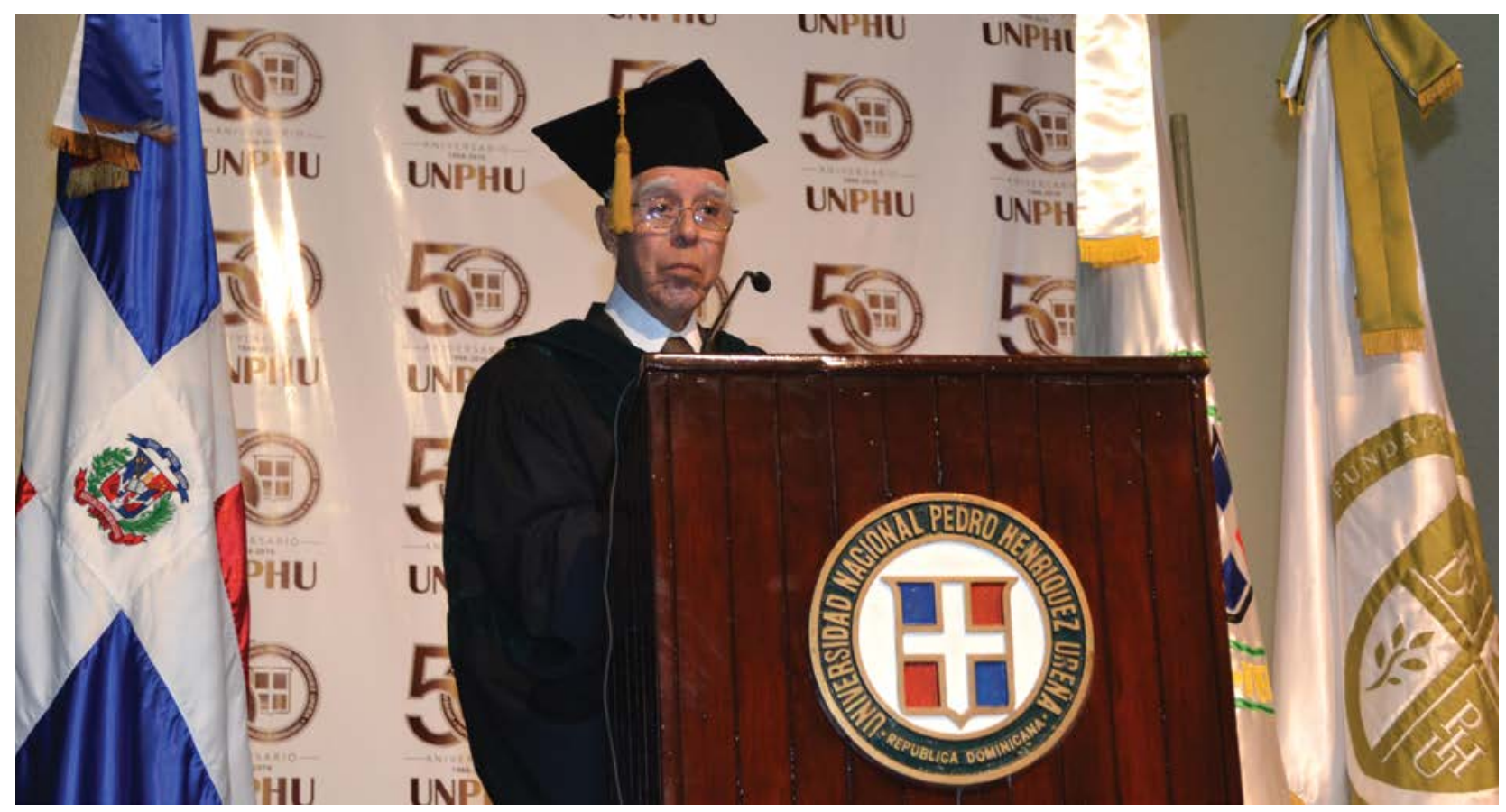

Imagen I. Arq. Eugenio Pérez Montás mientras dictaba el discurso "Los Tres Colosos".

La construcción del sistema educativo y su estructura se rige por ideas firmes; estrategias planificadas; competencias definidas; y solidaridad conceptual que articulan un proyecto complejo, cambiante y competitivo; esencia de cualquier gestión educativa necesariamente flexible y liberal, donde para sobrevivir no basta con ocupar un sitio en una larga fila de protagonistas...

Se necesita entrega, dedicación, capacidad de ver más allá de lo aparente, una visión que penetre el futuro y actúe sobre el presente fracturando la mediocridad para crear una nueva generación. Ese es su momento de alarde y vanguardia en una institución que es una metáfora de tolerancia regida por una ética basada en estatutos, reglamentos, normas y principios humanísticos.

\section{Transgresiones, intransigencias y} solidaridad

Junto a la mesa donde redactaba este LAUDATIO ACADÉMICO, apareció un artículo en el que un periodista reflexionaba sobre un colega fallecido, a quien recordaba asaltando un liceo secundario; actuando en protestas de obreros; defendiendo los derechos de los humildes o al amigo y compañero que dejó de creer en la revolución, pero que nunca dejó de indignarse.

El artículo: "Un contemporáneo fundamental" (Lévy, 2015), son reflexiones sobre André Glucksmann, ${ }^{1}$ filósofo y ensayista francés de origen judío austríaco, miembro de la Academia Europea de Ciencias y Artes. El autor: 
Bernard-Henri Lévy, filósofo y escritor nacido en la Argelia francesa, en el seno de una familia judía sefardí. ${ }^{2}$ Periodista de guerra que preside desde 1993 el Consejo de Supervisión del canal de televisión franco-alemán ARTE (Asociación Relativa a la Televisión Europea). ${ }^{3}$

Michel Foucault ${ }^{4}$ (a quien conocimos bajo el prisma del Seminario de Arquitectura Latinoamericana,S.A.L.), admirador de Glucksmann, veía en él una traducción exacta del axioma según el cual "todo parte, no del poder, sino del espíritu de resistencia...” (1967). Con su reflexión, Lévy nos hace pensar en la indignación de hoy; nos recuerda cómo nos indignábamos ayer y cómo lo haremos mañana, reforzando el espíritu de solidaridad que se percibe en esta reunión; y el derecho a encolerizarnos cuando sea necesario que rige el comportamiento de los hombres libres.

Hubo un tiempo en que se rompió la cohesión colectiva; la misma quedó en suspenso. Los valores tradicionales dejaron de funcionar, mientras emergieron intereses diversos. La presencia de una estructura débil facilitó su fractura; un estado "anómico", fenómeno que opera habitualmente en medio de una crisis de liderazgo. Luego la vanguardia se impuso y restauró el orden.

\begin{abstract}
Al iniciar estas semblanzas, vale la pena recordar el pasado, porque cuando esto ocurrió ellos estaban aquí, en la casa de los audaces; hogar de los emprendedores; territorio de los valientes, de los que corren riesgos; sitio de los que tropiezan dos veces $\mathrm{y}$ se levantan reiniciando su andadura; este: el lugar de los guerreros, donde el pensamiento domina la narración.
\end{abstract}

En esta ocasión la Junta Administrativa del Sistema y el Consejo Académico de la Universidad reconocen a tres ciudadanos, cuyos nombres quedarán grabados con letras mayúsculas en una piedra cúbica de grandes proporciones sumergida en los jardines místicos de este recinto.

Un exaedro virtual, como aquel creado por el ingenio de los arquitectos de Felipe II, oculto en el trazado del monasterio que Juan de Herrera describió en un manuscrito del que se conservan dos copias en la biblioteca de $E l$ Escorial ${ }^{5}$ (Taylor, 1992), y que se conoce con el nombre "Discurso de la figura cúbica" según los principios del arte de Ramón Llull. ${ }^{6}$

Los tres se distinguen por su espíritu de resistencia;

Por su individual noción de éxito;

Por su preocupación por los demás;

Por el justo sentido de su liderazgo;

Su protagonismo dedicado al bien común;

Por el manejo del poder como un emblema de la justicia.

¡Tres colosos!, que forman parte de una generación ubicada en medio de la ira...

"Generación tormenta" porque

conservan su capacidad de indignarse.

¡Tres colosos!, que han alcanzado cumbres donde rige el código de los trashumantes, el superlativo dominio del autodidacta; la soberanía alcanzada con la sabiduría de la primera escuela...; y con la experiencia vivida en su Alma Mater, la de Pedro Henríquez Ureña.

Nacieron en la década del treinta; transitaron aquellos tiempos donde todo era soberbia. Fueron testigos privilegiados de conversaciones secretas; diálogos de aposento en recámaras oscuras, como aquellas a las que muy pocos podían acudir, para medir el estado de ánimo de la nación. 
Una noche los comisionados se trasladaron al monasterio; atravesaron la "galería de las intrigas", morada de personajes singulares creados por la iconografía de Bruegel el Viejo, penetraron al "Recinto de los siete pecados", un oratorio desde donde se veía una biblioteca y un museo: el "Lugar de la cordura". Después recorrieron el corredor de los ARREPENTIDOS, monarquía de la contrición y el "pasillo del sentido común". Finalmente, penetramos a la "antesala de la esperanza".

Inclinados ante la venda transparente de un sobreviviente místico;

Encendimos el fuego para convertir la esperanza en certeza.

Aquella noche se escribió una carta al filo del destino;

Un poema para evitar el suicidio; y recobrar el alma;

Mirando el pantocrátor de un tímpano románico y medieval.

\section{Semblanza de Andrés Avelino}

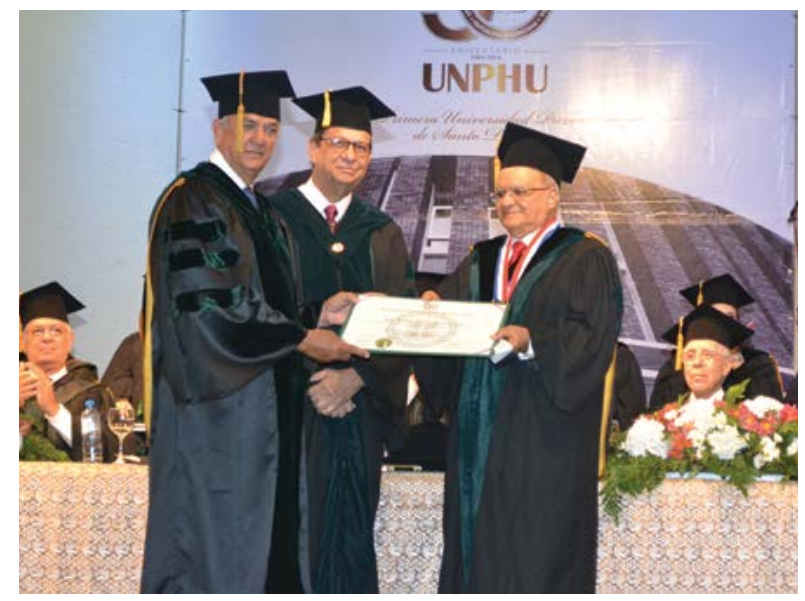

Imagen II. Arq. Raúl De Moya y Arq. Miguel Fiallo Calderón entregan al Sr. Andrés Avelino Abreu el diploma que lo acredita como Doctor Honoris Causa.

Su semblanza la escribió él mismo, paso a paso, desde su alumbramiento en Jarabacoa, el día 8 de abril, día de San Pompilio (el taumaturgo que obra prodigios, milagros), y de San
Dionisio de Corinto. Lleva el nombre venerable de un santo canonizado por Clemente XI en 1712, dotado de admirable conocimiento de la palabra de Dios.

De ahora en adelante, los capítulos de la misma quedarán en manos de sus hijos Rosa Milagros, Ariadna María y Andrés Avelino.

Andrés Avelino Abreu, empresario extraordinario realizó sus estudios primarios en la escuela Manuel Ubaldo Gómez, en Jarabacoa. La intermedia y la secundaria las hizo bajo la tutoría de maestros, en el mismo municipio.

En su hoja de vida aparece como Miembro del Consejo de Directores del Banco Popular Dominicano; Consejo de Directores del Grupo Popular; Consejo Nacional de la Empresa Privada (CONEP); Cámara Americana de Comercio;CámaradeComercioDomínico-Alemana; Cámara de Comercio Domínico-Japonesa; Cámara de Comercio de China-Taiwan; Miembro de la Cámara de Comercio Domínico-Mexicana; Cámara de Comercio Británica; Presidente en varias ocasiones la Cámara de Comercio Domínico Coreana; Tesorero, Comisario, Asesor y Consejero de la Fundación Universitaria Dominicana Pedro Henríquez Ureña (FUDPHU).

Reconocido por la "Feria de emprendedores", declaró sentirse orgulloso de ser pionero en su rama. Aconseja aprender a escuchar y recomienda fortalecer el trabajo en equipo (Lora, 2016, p.43).

Recio de carácter;

Mirada profunda y actitud felina;

Apuesta a la innovación,

a la competitividad;

Se inclina ante el reto productivo

y el crecimiento económico 
Curriculum vitae de Mario

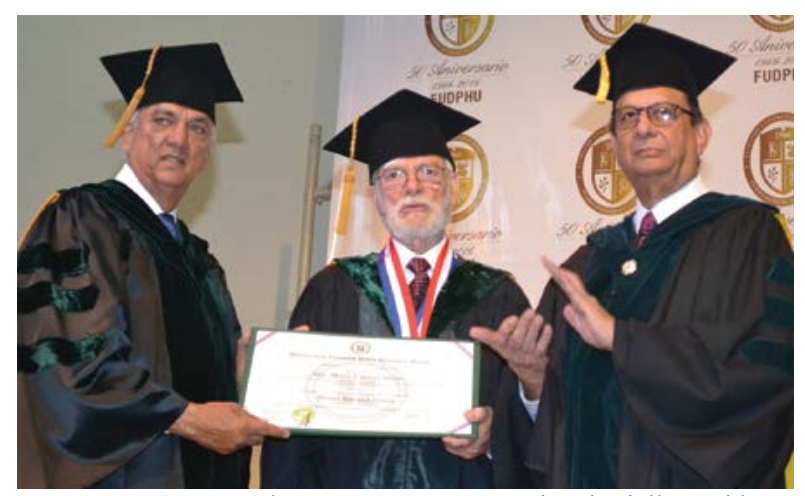

Imagen II. Arq. Raúl De Moya y Arq. Miguel Fiallo Calderón entregan al Sr. Mario Cabrera Morín el diploma que lo acredita como Doctor Honoris Causa.

El Curriculum Vitae de Mario, de etimología incierta por sus raíces etruscas, se remonta a Moca, un 21 octubre, Día de San Gerardo (que quiere decir valiente en la defensa). Su redacción está en las manos de sus hijos María de la Concepción, Ana Auristela, María de las Mercedes y Mario José.

Sus estudios primarios están registrados en Moca. Los secundarios en Estados Unidos y Canadá. Asistió al Colegio Loyola de la Universidad de Montreal, hoy Concordia University, donde se graduó de Ingeniero Químico en 1957.

Fue secretario de la Cámara Oficial de Comercio Agricultura e Industria del D. N; Presidente de la Fundación Dominicana de Desarrollo; Presidente de la Asociación de Industrias; Presidente del Consejo Nacional de Hombres de Empresa y Miembro del Consejo de Directores de la Corporación de Fomento Industrial.

Caballero de Gracia Magistral de la Soberana y Militar Orden de San Juan de Jerusalén Rodas y Malta. Fue presidente en dos ocasiones de la Junta de Administración de la Fundación Universitaria Dominicana y del Consejo de Dirección de la Universidad Nacional Pedro Henríquez Ureña.
Hombre libra-abril ilumina su mansión. Apasionado de la naturaleza y las humanidades, pensó siempre en la educación y sus reformas.

\section{Biografía de Rafael Vitelio}

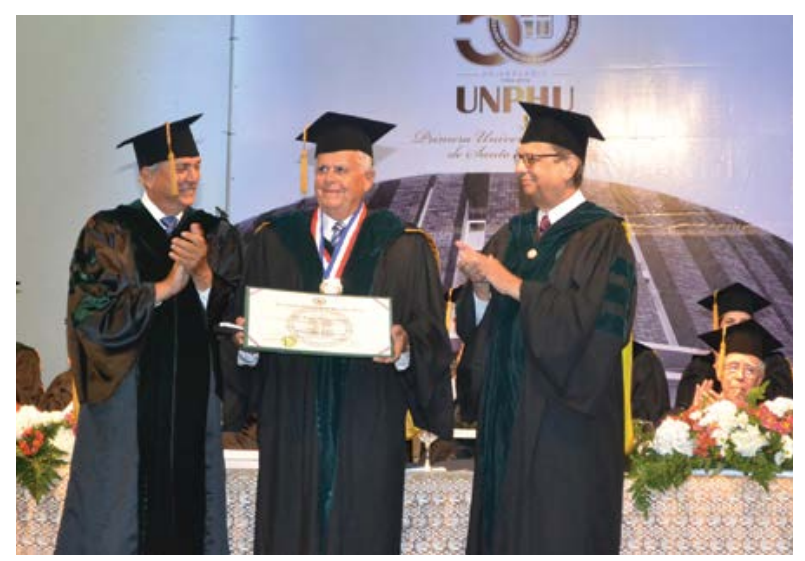

Imagen III. Arq. Raúl De Moya y Arq. Miguel Fiallo Calderón entregan al Sr. Rafael Bisonó Genao el diploma que lo acredita como Doctor Honoris Causa.

La biografía de Rafael Vitelio se inicia el 15 de abril de 1936, día de San Ezequiel (que significa Dios es fuerte), en Navarrete, Santiago de los Caballeros. Lleva el nombre de un arcángel, a quien el Islam considera el responsable de anunciar la fecha del Juicio Final.

Su biografía puede leerse en sus obras, y continúa redactándose en su descendencia: Carmen Altagracia (quien lleva el nombre de su madre); Rafael V.; Juan Antonio; Máximo Rafael; Sandra Margarita y María de Lourdes.

Obtuvo su educación básica e intermedia en los institutos Platón, Iberia y Ulises Francisco Espaillat, en Navarrete, Santiago de los Caballeros. Se graduó de ingeniero civil en la Universidad Autónoma de Santo Domingo, en 1957.

Miembro de una larga lista de organismos profesionales, y cargado de honores, ha creado una sólida organización para el desarrollo de la vivienda. No hay lugar en la geografía que no haya sido tocada por las iniciativas creadas 
por este recio instrumento para el desarrollo nacional, cuyos grandes objetivos coinciden con los retos globales del milenio: erradicar la pobreza extrema; integrar a todos en el progreso; dar alas al empleo de calidad y la innovación; y pensar en ciudades más habitables (El País, 2015, p.1).

Ha recibido numerosos premios y reconocimientos de la Cámara Dominicana de la Construcción y de la Organización Regional de Cámaras de la Construcción de Centroamérica. Fue condecorado por el presidente Danilo Medina con la Orden al Mérito de Duarte, Sánchez y Mella, en el Grado de Caballero, en el 2015. Por muchos años se ha desempeñado como tesorero de la Junta de Administración de la Fundación Universitaria Dominicana.

\section{Alarde, vanguardia y sacrificio}

Los tres guerreros que están siendo objeto del presente homenaje son desde ahora parte de una metamorfosis, pluralidad participativa de una entidad que ha querido crear un modelo que se inició en 1966. A partir de ahora iniciamos un nuevo ciclo en el que participan sus egresados, quienes tienen a su cargo la redacción de un discurso restaurador: un palimpsesto donde cada pensamiento responde a un código, de última generación, como los automóviles 0.0 ( 0 accidentes, 0 emisiones) exhibidos en el salón de Frankfurt en el año 2015 (Andrés Avelino Abreu, comunicación personal, 11 de diciembre de 2015).

Al asumir el más alto galardón que otorga la universidad y el sistema institucional que la propicia, pueden levantar la voz con un viejo grito de guerra:

Todo es crisis, tormenta, energía.

Todo es experiencia y sacrificio;

pensamiento, ideario.
Todo es vanguardia y desafío, vocación y nostalgia.

Al convertirse en doctores de esta academia, forman parte de un ejército anónimo de soldados que vivieron en pueblos mediterráneos donde había una calle larga con tramos rectos como el tiro de un cañón disparado por un artillero.

El sistema es testimonio, una metáfora de tolerancia, que aunque alguna vez pudo haber perdido parte de su alma, la recuperó desgarrando con soberbia la túnica negra que visten sus maestros, y rescatando una oración sagrada enterrada en sus cimientos: "Todo aquel que tenga algo que enseñar o aprender será bien recibido".

\section{Referencias}

Foucault, M. (Marzo, 1967). De los Espacios

Otros. Círculo de Estudios de Arquitectura. (Cercle des etudes architecturals). En: Architecture, Mouvement, Continuité, n 5, octubre de 1984. Traducida por Pablo Blitstein y Tadeo Lima. Recuperado de: http:// yoochel.org/wp-content/ uploads/2011/03/foucalt_de-losespacios-otros.pdf

Lévy, B-H. (2015, 12 de noviembre). Una reflexión en torno a André Glucksmann: un contemporáneo fundamental. El País. Recuperado de: https:// cultura.elpais.com/cultura/2015/11/11/ actualidad/1447270803_355896.html

Lora, E. (2016). El diálogo de dos titanes: Diálogo con Andrés Avelino Abreu y Pepín Corripio. Revista Emprendedores, 8 (231) enero - febrero. p. 42-44. Sección Vida Éxito. 
Retos Globales: El desafío de reconstruir el planeta. (3 de Octubre de 2015). El País. p.1

Taylor, R. (1992). Arquitectura y magia: Consideraciones sobre la idea de El Escorial. Madrid: Ediciones Siruela. La Biblioteca Sumergida.

\section{Notas}

1. ANDRÉ GLUCKSMANN. Filósofo francés, nacido el 19 de junio de 1937 en Boulogne-Billancourt. Su vida fue consagrada a la reflexión sobre la moral en política y la naturaleza del mal, sobre el trasfondo constante de una actualidad internacional cargada de conflictos, en los que nunca dudó en implicarse. Glucksmann observaba el mundo a la luz de su reconocido pesimismo. Para él, un intelectual debía ser siempre "un profeta del desastre", un visionario "capaz de vaticinar, en la propia semilla, la flor venenosa”. Su irrupción en el paisaje intelectual se produjo a mediados de los setenta, cuando despuntó como integrante de los llamados nuevos filósofos, mediático grupo de jóvenes pensadores entre los que figuraban Bernard-Henri Lévy y Christian Jambet. Entre sus obras se destacan: Una rabieta infantil, Occidente contra Occidente, Los dos caminos de la filosofía, Sócrates y Heidegger: ideas para un tiempo trágico y El discurso del odio. (El país, 10 de noviembre, 2015).

\section{BERNARD-HENRI LÉVY. Filósofo} francés y uno de los escritores más estimados y más vendidos en Europa. Es autor de más de 30 libros, incluyendo obras de filosofía, ficción y biografía. Vértigo americano: Viajar América en las huellas de Tocqueville. Su obra "Hotel Europa" es un grito de alarma por la crisis que afrontó el proyecto europeo y el sueño detrás de él. Lévy ganó renombre por su documental sobre el conflicto bosnio, Bosna! (1994). Después de comenzar su carrera como reportero de guerra de Combat, el legendario periódico fundado por Albert Camus durante la ocupación nazi de Francia, para lo cual cubrió la guerra entre Pakistán e India sobre Bangladesh, Lévy fue instrumental en la fundación del grupo de New Philosophers. Emprendió varias misiones diplomáticas para el gobierno francés. Siguió el rastro de Daniel Pearl en Pakistán para investigar su 'novela de investigación' Who Killed Daniel Pearl? (2003). Su libro La guerra, el mal y el fin de la historia (2004) le llevó a los sitios de lo que él llama las guerras olvidadas del mundo, desde Colombia a Sri Lanka. (IMDb, Bio. por Aline LBK, 2017).

3. ARTE. Como Cadena pública europea, ARTE diseña y emite programas culturales que propician la comprensión y el acercamiento entre europeos. Desde su creación en 1991, ARTE está comprometida con la diversidad cultural y el multilingüismo, convencida de que la mejora en la difusión de contenidos audiovisuales puede contribuir a la integración cultural europea. Arraigada en el presente, la Cadena contempla la actualidad mundial con una mirada europea, da prioridad a la investigación y aporta elementos para comprender y llegar más lejos. Fruto de la asociación entre Francia y Alemania, consta de tres entidades: la Central ARTE GEIE en Estrasburgo, ARTE France en París y ARTE Deutschland en Baden-Baden. (Arte en español, 2017).

4. MICHEL FOUCAULT. El 14 de marzo de 1967 fue dictada la conferencia "De los Espacios Otros", en el Círculo de Estudios de Arquitectura. (Cercle des etudes architecturals) y publicada en 1984. En la misma, el autor aborda la noción de heterotopía, que configura el contenido de los Anales 44 del Instituto de Arte Americano e Investigaciones Estéticas. Eugenio Pérez Montás (2016). Año 2016, 
Documentando la Arquitectura. "Memoria, Efecto, y Retroactividad del Seminario de Arquitectura Latinoamericana" (S.A.L. 2015). "Del Sincretismo a la Heterotopía". (ensayo en proceso).

5. JOVELLANOS. Fue el primero en llamar la atención sobre esta singular obra. Dio con un manuscrito de ella en el monasterio de Santa María de la orden del Císter cerca de Palma de Mallorca en el curso de su destierro a aque1la isla entre 1801 y 1808 y la copió entera. La primera hoja llevaba el título Discurso del señor Juan de Herrera, aposentador mayor de su majestad, sobre la figura cúbica. No se sabe el paradero ni del manuscrito ni de la copia hecha por Jovellanos. El manuscrito escurialense D-III-25 carece de Título, pero dentro tiene la inscripción siguiente: Declaración del cuerpo cúbico con algunas figuras al principio que es necesario penetrar y entender para la introducción del dicho cubo; no tiene este tratado nombre del autor, pero parece y lo es de Juan de Herrera, architecto y aposentador mayor del Rey don Phelippe nuestro señor. La primera edición impresa apareció en 1935, publica- da por la editorial Plutarco de Madrid, bajo el título de Discurso de la Figura Cúbica, con un prólogo de Julio Rey Pastor. Ibídem.

6. Esa piedra cúbica aparece en un fresco de la bóveda que cubre el coro alto de la iglesia del monasterio +. Es obra de Luca Cambiaso y tiene por tema LA GLORIA O VISIÓN DEL PARAÍSO. Ibídem.

7. PIETER BRUEGEL EL VIEJO (15251569). Dos grabados salidos de la imaginación Pieter Bruegel el Viejo, de hacia 1565 son la causa de que desde entonces la iconografía universal caracterice así a las brujas. Dos obras que, junto a otras del pintor holandés y de Durero y de óleos de Frans Francken II, David Teniers o Bruegel el Joven uno de sus hijos- se exhiben en Las Brujas de Bruegel, en el Hospital de San Juan, en Brujas (Bélgica), una muestra de casi un centenar de piezas cedidas por varios museos y bibliotecas de Europa que puede visitarse hasta finales de junio. Luis Mazarraza. "Las brujas vuelan gracias a Bruegel”. El País, 28 de marzo de 2016.

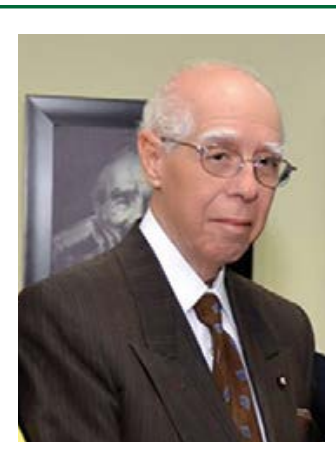

\section{Eugenio Pérez Montás}

Doctor Honoris Causa en Arquitectura en 1985 otorgado por la Universidad Nacional Pedro Henríquez Ureña de la cual es profesor fundador, asesor vitalicio y Miembro del Comité Editorial. Además, Miembro de Número de la Academia de Historia. Director General del Patronato de la Ciudad Colonial de Santo Domingo. Miembro Fundador del Capítulo Dominicano del Consejo Internacional de Monumentos y Sitios (ICOMOS). Miembro Fundador del Capítulo Dominicano del Consejo Internacional de Museos (ICOMOSUNESCO). Estudios de la Ciudad Colonial de Santo Domingo, en 1999, B.I.D. Presidente actual y Miembro Fundador del Plan del Gran Caribe para los Monumentos y Sitios (CARIMOS), 2015. Comendador de la Orden San Gregorio Magno, Siendo papa Paulo VI en 1977. Comendador de la Orden Isabel La Católica, Reinado Juan Carlos I, en 1976. Orden de la Letras y las Artes (1978): Orden de Palmas Académicas (1994) Gobierno de Francia (Ambas en el grado de Oficial): Medalla de Bronce, Asociación Iberoamericana de Zoológicos, Barcelona en 1978. Premio Nacional de Historia Juan Pablo Duarte, en 1999. Gran Premio Bienal, 2000. Premio Fundación Corripio, Categoría Arquitectura, 2007. Premio América Patrimonio, Patrimonio Viviente de la Arquitectura, Sociedad de Arquitectos de la República Dominicana, 2014. Seminario de Arquitectura Latinoamericana, 2016. Dedicatoria como escritor de una calle rotulada con su nombre en la Feria del Libro, 2011. Entre sus publicaciones se destacan: Monumentos y Sitios del Gran Caribe, Restauración de Antiguos Monumentos Dominicanos: Planos e imágenes: Monumentos Históricos y Arqueológicos; Biografía de un Monumento, La Ciudad del Ozama, Ensayo Clásico. 